\title{
CARACTERIZAÇÃo FISIONÔMICO-FLORÍSTICA E MAPEAMENTO DA vegetação da Reserva Biológica de Poço das Antas, Silva Jardim, Rio de Janeiro, Brasil
}

\author{
Haroldo C. de Lima ${ }^{1}$, Solange de V. A. Pessoa, \\ Rejan R. Guedes-Bruni ${ }^{1}$, Luis Fernando D. Moraes ${ }^{2}$, \\ Sérgio V. Granzotto ${ }^{1}$, Shoji Iwamoto ${ }^{1}$ \& Jorge Di Ciero ${ }^{1}$
}

\section{Resumo}

(Caracterização fisionômico-florística e mapeamento da vegetação da Reserva Biológica de Poço das Antas, Silva Jardim, Rio de Janeiro, Brasil) Os tipos de vegetação ocorrentes na área da Reserva Biológica de Poço das Antas, estado do Rio de Janeiro, Brasil (22 $30^{\circ}$ e $22^{\circ} 33^{\prime} \mathrm{S}$; $42^{\circ} 15^{\prime}$ e $42^{\circ} 19^{\prime} \mathrm{W}$ ) foram identificados, descritos e mapeados. Foram identificadas seis unidades fisionômicas, sendo duas florestais (floresta aluvial e floresta submontana) e quatro não florestais (formação pioneira com influência fluvial, capoeira aluvial, capoeira submontana e campo antrópico). As características fisionômicas e florísticas mais relevantes de cada unidade foram descritas e discutidas com base na análise comparativa entre as seis unidades fisionômicas e com outros trechos de mata atlântica. O mapeamento foi realizado com emprego de fotointerpretação analógica, em escala de 1:20.000. Na avaliação da cobertura vegetal atual foram estimados 2.608 hectares de remanescentes florestais em variados estados de preservação (floresta aluvial - 17,9\% e floresta submontana $-34,3 \%$ ), indicando a expressiva representatividade de formações não florestais com influência fluvial (20,0\%) ou antrópica $(27,9 \%)$.

Palavras-chave: mapa de vegetação, mata atlântica, composição florística, fito-fisionomia

\section{AbStract}

(Physiognomic-floristic characteristics and vegetation map of the Poço das Antas Biological Reserve, Silva Jardim, Rio de Janeiro, Brazil) Six vegetation types are described for Poço das Antas Biological Reserve, Rio de Janeiro State, Brazil (22 $30^{\prime}$ ' e $22^{\circ} 33^{\prime} \mathrm{S}$; $42^{\circ} 15^{\prime}$ e $42^{\circ} 19^{\prime} \mathrm{W}$ ). Two forest formations (alluvial forest and submontane forest) and four non-forest formations (fluvial pioneer, alluvial scrub, submontane scrub and manmade grasslands) were identified. Relevant floristic and physiognomic characteristics of each unit are described and compared to analogous Atlantic Rain Forest formations. The vegetation was mapped using analog photo interpretation on a scale of 1:20,000. An estimated 2,608 ha of forest remnants in various states of preservation were detected (alluvial forest $-17.9 \%$; submontane forest- $34.3 \%$ ), plus a significant representation of non-forest formations with fluvial influence (20.0\%) and manmade interference (27.9\%). Key words: vegetation map, Atlantic Forest, floristic composition, physiognomy.

\section{INTRODUÇÃo}

No estado do Rio de Janeiro a planície costeira é caracterizada por uma grande heterogeneidade da paisagem, possivelmente em muito influenciada por fatores físicos como variações na topografia - morros, colinas e planícies bem como no regime de inundação do solo. Estes ambientes distintos, capacitados a abrigarem populações de diferentes espécies, através do seu componente vegetal, responderiam por esta heterogeneidade, resultando, por sua vez, num mosaico vegetacional com alta diversidade e heterogeneidade florística (Guedes-Bruni 1998).

Embora muito pouco se conheça sobre a cobertura vegetal original da bacia do Rio São João, pode-se admitir que a região ostentava exuberante floresta (IBDF/FBCN 1981). Um antigo relato do início do século XIX menciona que as ribanceiras estavam "bastante cobertas de arvoredo" (Luccock 1951). É provável que esta vegetação original tenha permanecido

Artigo recebido em 11/2005. Aceito para publicação em 05/2006.

${ }^{1}$ Instituto de Pesquisas Jardim Botânico do Rio de Janeiro. Rua Pacheco Leão 915, 22460-030, Rio de Janeiro, RJ, Brasil. hlima@jbrj.gov.br

${ }^{2}$ Instituto Brasileiro do Meio Ambiente e dos Recursos Naturais Renováveis. 
pouco alterada até cerca da metade do século XX (Lamego 1946), quando tem início a destruição de amplos trechos de floresta nos morros e nas planícies. Atualmente são raros os trechos com vegetação natural, que em contraste com grandes áreas alteradas, são testemunhos da drástica destruição pelas atividades antrópicas.

A Reserva Biológica de Poço das Antas apresenta hoje um aspecto fitofisionômico bastante empobrecido quanto a sua cobertura vegetal primitiva. A ação antrópica, principalmente pela exploração seletiva de essências florestais e pelo fogo, além da drenagem artificial e retificação dos rios, contribuiu para o desaparecimento de amplos trechos de formações florestais, sobretudo, nas planícies de inundação. No mapeamento da vegetação e análise dos aspectos florísticos realizados no final da década de 70 (Carauta et al. 1978), a cobertura vegetal da área foi reconhecida como, em geral, secundária e os remanescentes classificados como floresta pluvial. Posteriormente, na diagnose elaborada para subsidiar o plano de manejo (IBDF/ FBCN 1981) foram reconhecidos e descritos quatro tipos de vegetação (florestal, campestre, brejal e aquático) existentes nesta unidade de conservação. Entretanto, face às mudanças ocorridas na área, particularmente em decorrência dos freqüentes incêndios ocorridos nos últimos anos, há necessidade de uma urgente reavaliação.

Em decorrência desta situação, torna-se imperativa a atualização de dados sobre a vegetação desta unidade de conservação, prioritariamente no que concerne a sua natureza e extensão. Estas informações são imprescindíveis ao adequado manejo e implementação de ações de restauração ecológica das áreas degradadas. São ainda urgentes para apoiar estratégias para estabelecimento de medidas efetivas de proteção das áreas naturais remanescentes. Vale ressaltar que estudos desta natureza têm se mostrado ferramentas fundamentais para integrar diferentes disciplinas relacionadas à análise ambiental, principalmente para subsidiar o manejo em unidades de conservação (Noffs \& Baptista-Noffs 1982;Oliveira \& Porto 1999; Cardoso-Leite et al. 2005).

Tendo em vista tratar-se de um dos últimos remanescentes de formação florestal de planície costeira no estado do Rio de Janeiro, embora já bastante fragmentada, foram implementados estudos no sentido de levantar dados para a caracterização fisionômico-florística das áreas ocupadas pelos diversos tipos de cobertura vegetal, incluindo as áreas degradadas. Neste contexto, considerando ainda a necessidade urgente de um documento norteador das ações de proteção e manejo, priorizou-se a geração de um mapa temático que pudesse auxiliar: (1) na definição de áreas prioritárias para estudo; (2) na implantação de modelos para expansão de áreas florestadas ou mesmo de seu enriquecimento; (3) no monitoramento de processos que decorram em futuras, e nem sempre improváveis, modificações de sua paisagem, sobretudo em decorrência do fogo.

\section{Material e Métodos}

\section{Área de estudo - Reserva Biológica de Poço das Antas (Rebio)}

A Rebio encontra-se localizada politicamente na região das baixadas litorâneas do estado do Rio de Janeiro, no município de Silva Jardim, e geograficamente em extensa planície na região central do estado, outrora designada baixada de Araruama (2230' e

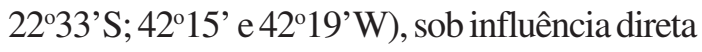
da bacia hidrográfica do rio São João e com área aproximada de 5.000 hectares (Fig. 1). Criada pelo Decreto ${ }^{\circ} 73.791$ de 11.03.1974 (IBDF/ FBCN 1981) a área da Rebio foi, no passado, como as demais áreas da bacia do rio São João, explorada pela retirada de madeira, implantação de atividades agrícolas, bem como pecuária (Cunha 1995, Primo \& Volcker 2003).

As manchas de floresta remanescentes são resultantes dos processos sucessionais que ali se deram, em diferentes épocas e distintos usos do solo, por ocasião da expansão agrícola que ocorreu ao norte do Rio de Janeiro. Não só 
a construção da ferrovia Estrada de Ferro Leopoldina, ligando o norte do estado à cidade do Rio de Janeiro, interferiu na paisagem local como o aumento da exploração de madeira, para abastecimento das fornalhas das locomotivas, acentuaram a supressão da floresta.

A construção da represa de Juturnaíba, por sua vez, ainda que situada em área limítrofe, na sua porção sudeste, promoveu forte impacto sobre a cobertura vegetal da Rebio. A obra foi iniciada no final da década de 70 e concluída em 1984. As mudanças na altura do lençol freático, bem como as sucessivas retificações do canal do rio São João foram as que mais interferiram sobre o ambiente biofísico (Cunha 1995).

A cobertura vegetal atual da Rebio, embora nitidamente fragmentada, representa um significativo remanescente florestal de baixada do estado do Rio de Janeiro, não só pelos elementos típicos à esta fisionomia vegetal, como também por abrigar populações do mico-leãodourado (Leonthopithecus rosalia rosalia L.), espécie ameaçada de extinção (Guedes-Bruni 1998). As populações desta espécie presentes na Rebio dependem intimamente da ampliação de áreas de floresta, seja por processos naturais, seja por ações orientadas de restauração ecológica, como as implementadas pelo Programa Mata Atlântica do Jardim Botânico do Rio de Janeiro desde 1993.

A topografia é predominantemente de planície, com a presença de morros e morrotes de perfis arredondados, também chamados de meias-laranjas ou mamelonares, com alturas que variam de 19 a 200 metros, e que são separados por várzeas de fundo achatado e alagadiças (Figs. 2 e 3) (IBDF/FBCN 1981). Takizawa (1995) reconheceu sete compartimentos geomorfológicos na Rebio:

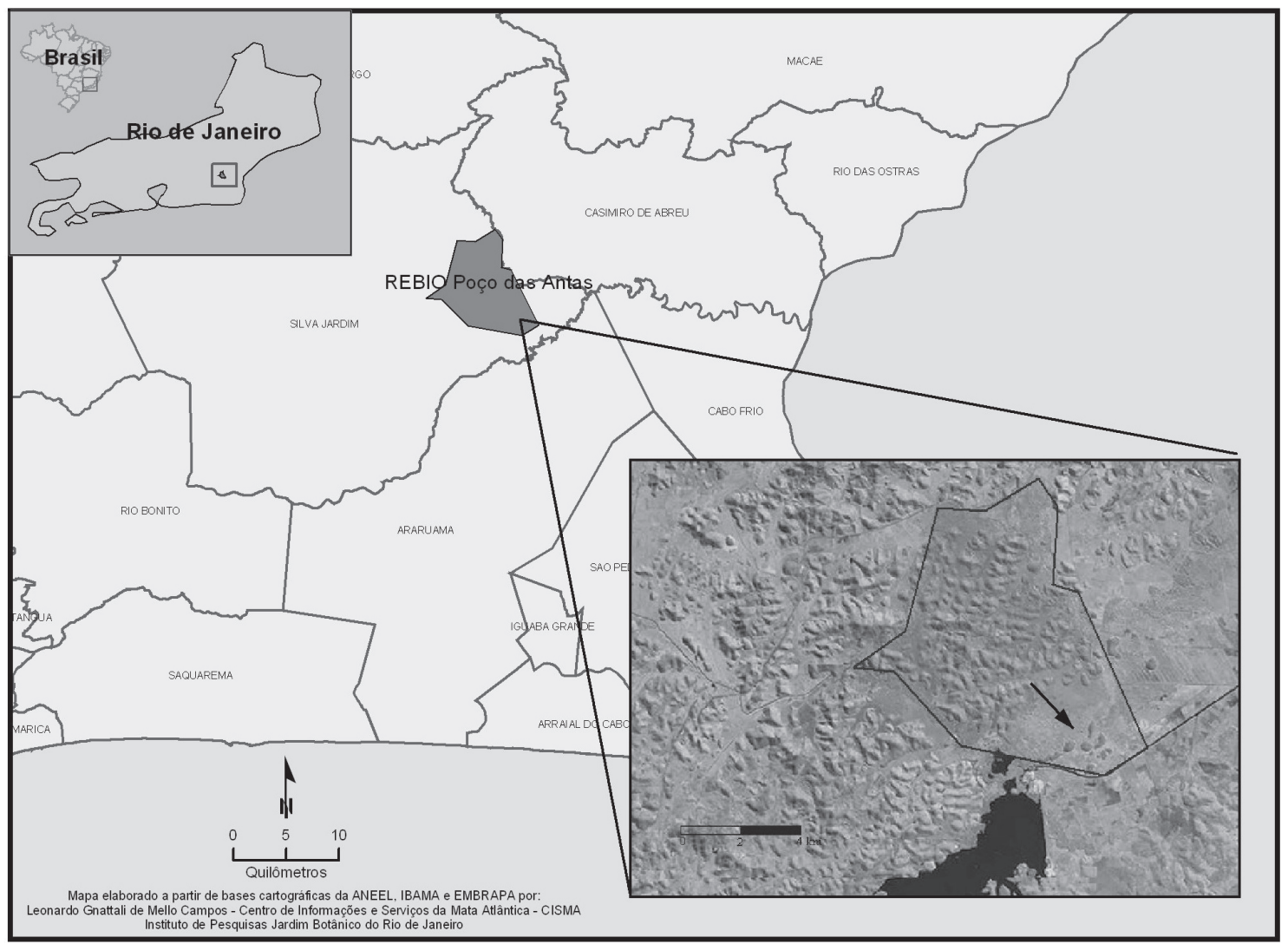

Figura 1 - Localização geográfica da Reserva Biológica de Poço das Antas, Silva Jardim, Rio de Janeiro. 
faixa meândrica, várzea interna, várzea externa, alvéolos, morrotes baixos, morrotes altos e morros. O rio São João é o principal curso d'água da Rebio e seus afluentes (Aldeia Velha, Preto e Iguapé) percorrem grande parte da Reserva, inundando as áreas de várzea.

Os limites da Rebio encontram-se em pleno domínio das planícies terciárias e quaternárias, ocorrendo rochas datadas do
Pré-Cambriano, bem como rochas típicas do Complexo do Litoral Fluminense (IBDF/ FBCN 1981).

As classes de solos (EMBRAPA 1999) estão distribuídas basicamente entre os solos de elevações, que são os Argissolos e os Cambissolos; e os solos de várzea, que são os Gleissolos, os Neossolos Flúvicos e os Organossolos. Ocorre um predomínio de solos álicos e, à exceção dos Neossolos Flúvicos e

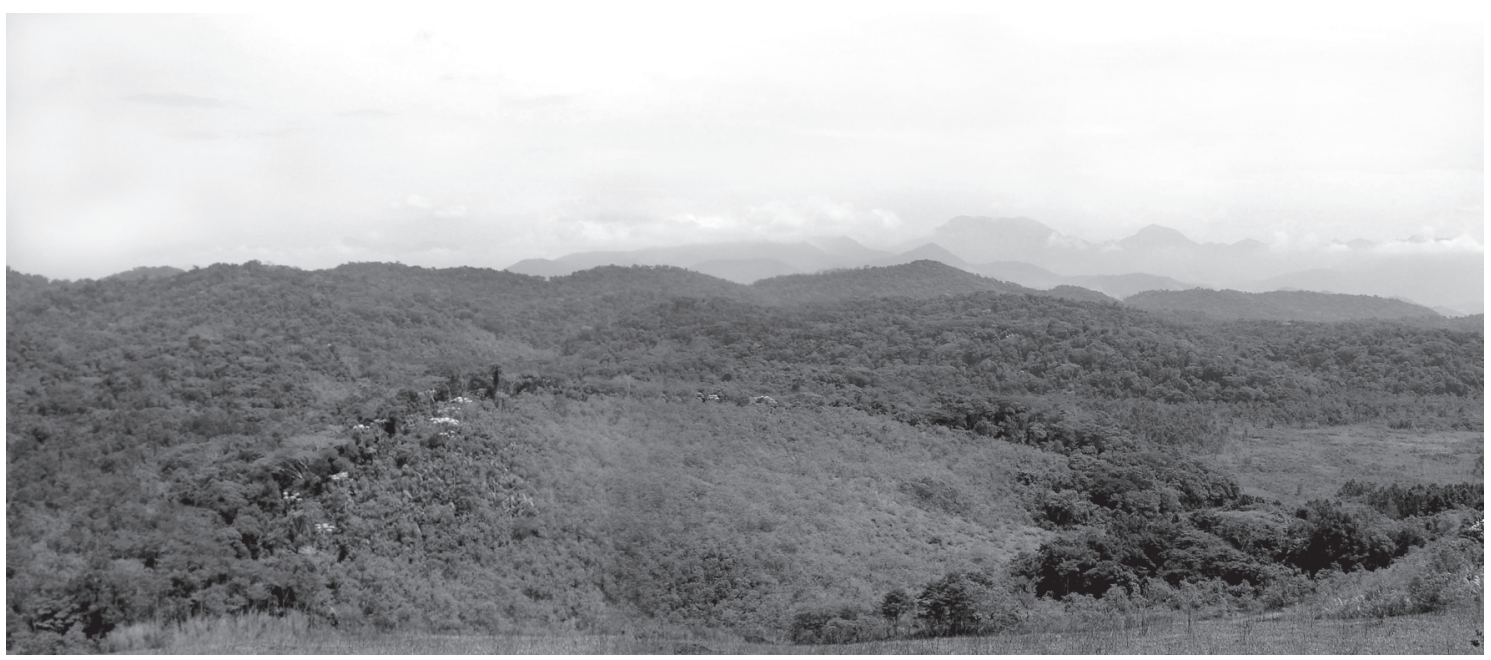

Figura 2 - Vista geral de trecho com morros e morrotes de perfis arredondados na Reserva Biológica de Poço das Antas, Silva Jardim, Rio de Janeiro.

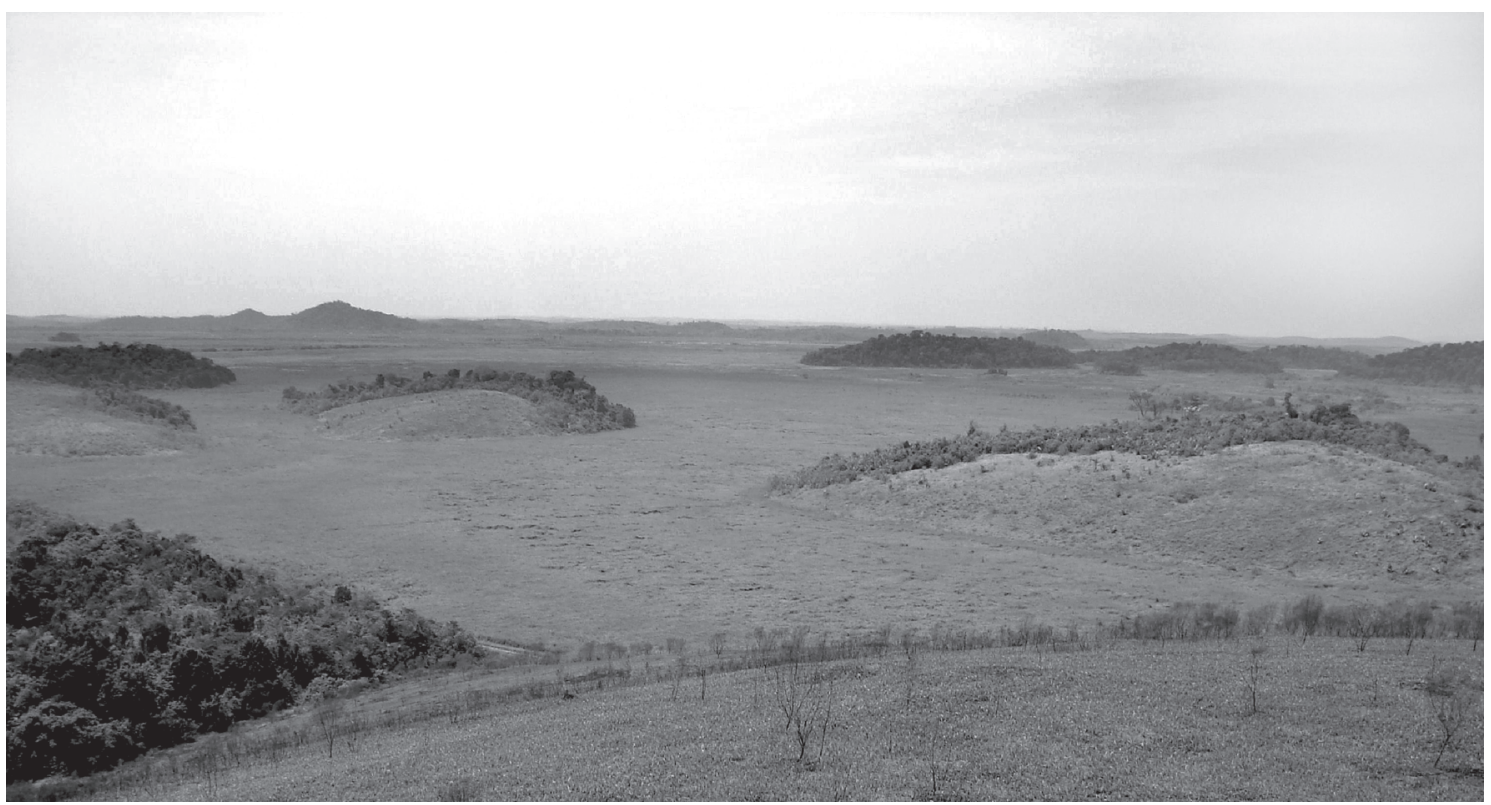

Figura 3 - Vista geral de um trecho de planície com morrotes isolados na Reserva Biológica de Poço das Antas, Silva Jardim, Rio de Janeiro. 
dos Organossolos, os demais possuem textura argilosa (Takizawa 1995).

O clima regional é do tipo megatérmico úmido (B2A') na classificação de Thornthwaite \& Mather, correspondendo à designação de tropical chuvoso com estação seca no inverno (As) de Köeppen (Bernardes 1952). O diagrama ombrotérmico referente ao período de janeiro de 1993 a dezembro de 2002 (Fig. 4) assinala os meses de junho a agosto como representantes do período menos chuvoso e de temperaturas menos elevadas, correspondendo os meses de novembro a março ao período mais chuvoso e de maiores temperaturas. Os demais meses representam situações intermediárias entre os dois períodos (Pessoa 2003).

Neste intervalo de dez anos, a temperatura média anual foi de $25,5^{\circ} \mathrm{C}$, sendo registrada no mês de julho a temperatura média mais baixa de $21,8^{\circ} \mathrm{C}$ e a maior temperatura média durante os meses de janeiro e fevereiro $\left(29^{\circ} \mathrm{C}\right)$. Em relação à precipitação, foi observado no período um valor médio anual de 1994,9 mm, correspondendo ao mês de dezembro o maior índice $(320 \mathrm{~mm})$ e o menor valor $(38,9 \mathrm{~mm})$ ao mês de julho.

\section{Caracterização fisionômico-florística}

\section{Unidades fisionômicas}

Para os estudos sobre a vegetação foi adotado o sistema de classificação fisionômico-ecológico proposto por Veloso \& Goes-Filho (1982), que também foi usado como referência para o Mapa de Vegetação do Brasil (IBGE 1992). De acordo com o sistema e o mapa acima citados, a cobertura vegetal da Rebio representa um trecho de Floresta Ombrófila Densa. Este tipo de vegetação foi subdividido em seis formações obedecendo a uma hierarquia topográfica e fisionômica: floresta aluvial, floresta submontana, formação pioneira com influência fluvial, capoeira aluvial, capoeira submontana e campo antrópico. Com base nesta conceituação das formações, foram realizados os estudos para reconhecimento, delimitação, mapeamento e descrição das unidades fisionômicas da cobertura vegetal da

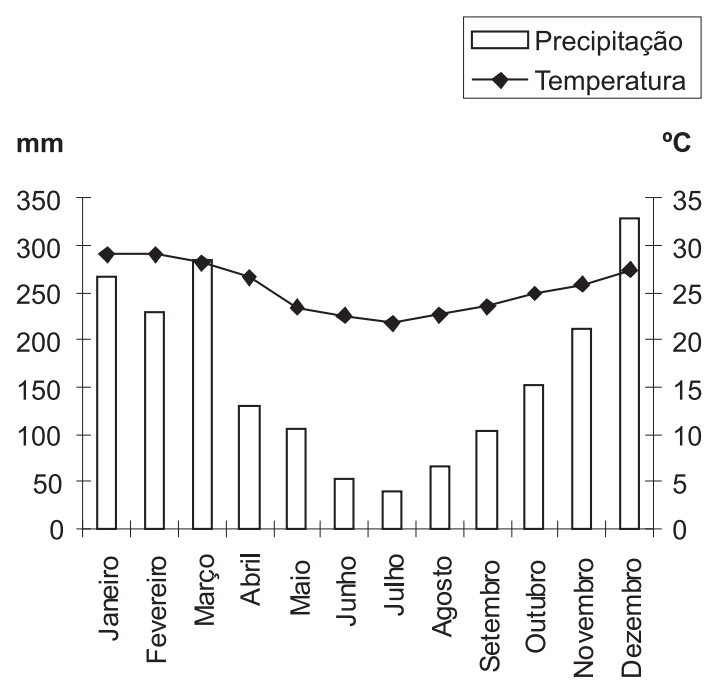

Figura 4 - Distribuição dos totais mensais de precipitação e das temperaturas médias mensais, na série temporal de 1993 a 2002 para a Reserva Biológica de Poço das Antas, Silva Jardim, Rio de Janeiro.

Rebio. Em acréscimo ao sistema adotado, foi considerado ainda uma terminologia própria para o reconhecimento das áreas de vegetação secundária em fases iniciais de regeneração.

\section{Levantamento florístico}

Para análise da composição florística das diferentes fisionomias foram realizados estudos de campo no período de 1993-1999, efetuando-se o levantamento e a coleta de material botânico das espécies mais representativas de cada unidade fisionômica. Foram também colhidas informações com antigos moradores locais sobre os impactos antrópicos na área e documentadas, por meio de fotografia, as diferentes fisionomias naturais e alteradas e as espécies mais representativas.

Dados complementares sobre a composição florística foram obtidos nos resultados dos estudos de campo dos vários projetos desenvolvidos pelo Programa Mata Atlântica (PMA) na Rebio. Os estudos sobre estrutura e composição de trechos de floresta aluvial e submontana utilizaram unidades amostrais de 1 hectare, subdivididas em parcelas de $25 \times 50 \mathrm{~m}$, onde foram inventariados os indivíduos com diâmetro a altura do peito (DAP) igual ou maior que $5 \mathrm{~cm}$. Em trechos de 
vegetação arbustivo-herbácea, os estudos utilizaram o método de pontos (Mantovani 1987). Estes dados estão armazenados no Banco de Dados do PMA e atualmente gerenciados pela equipe da Assessoria de Informática e Geoprocessamento do Instituto de Pesquisas Jardim Botânico do Rio de Janeiro.

\section{Mapeamento}

A metodologia do mapeamento da cobertura vegetal teve por base a fotointerpretação. Após o levantamento dos recobrimentos aerofotogramétricos disponíveis e a seleção dos mais adequados, optou-se pela cobertura realizada em 1988 pela PROSPEC S.A, com fotografias aéreas em escala aproximada de 1:20.000. A delimitação da área da unidade de conservação foi realizada sobre o foto-índice para identificação das fotografias aéreas relevantes ao estudo.

O trabalho teve início com a delimitação das áreas úteis de cada foto e a identificação dos diferentes padrões de cobertura e uso do solo em papel poliéster transparente, o que resultou em um mapa preliminar na escala de 1:20.000. Posteriormente, o mosaico aerofotogramétrico e o mapa base de cobertura e uso do solo foram ampliados para escala 1:10.000 para realizar a análise da cobertura vegetal e uso do solo. As características da paisagem analisadas para o reconhecimento dos padrões de cobertura e uso do solo foram: fisionomia, altimetria, regime hídrico e grau de interferência antrópica. Dados complementares referentes à geomorfologia, geologia, declividade e solos foram obtidos no Plano de Manejo (IBDF/
FBCN 1981) e no Levantamento Pedológico e Zoneamento Ambiental (Takizawa 1995) da Rebio. As bases cartográficas complementares utilizadas foram as folhas topográficas do IBGE na escala de 1:50.000 (SF-23-Z-B-VI1 - Silva Jardim; SF-23-Z-B-VI-2 - Morro de São João; SF-23-Z-B-III-3 - Quartéis).

Após a definição das diferentes unidades fisionômicas, foram realizados estudos para correlação de campo, revisão dos limites das unidades de cobertura vegetal, confecção do mapa final (Anexo 1) e quantificação das áreas mapeadas segundo as unidades de legenda (Tab. 1).

\section{Resultados e Discussão}

A paisagem atual na Rebio está representada por áreas de cobertura vegetal natural ou antrópica, cujas fisionomias de modo geral refletem, algumas mais outras menos, os processos antrópicos decorrentes de épocas pretéritas. De modo geral, esta situação é muito semelhante àquela já descrita por Carauta et al. (1978) e IBDF/FBCN (1981), principalmente em relação as mudanças promovidas pelos impactos da construção da Represa de Juturnaiba,

Embora situada na região fitoecológica da Floresta Ombrófila Densa (Veloso \& GoesFilho 1982; IBGE 1992), a cobertura vegetal desta unidade de conservação, juntamente com grande parte da bacia do Rio São João e arredores, foi reconhecida como um trecho de vegetação secundária e de atividades agrárias no mapeamento da vegetação na escala 1:250.000 do Projeto RADAMBRASIL (Ururahy et al. 1983). A escala utilizada por

Tabela 1 - Área e percentual de cobertura das unidades fisionômicas ocorrentes na área da Reserva Biológica de Poço das Antas, Silva Jardim, Rio de Janeiro.

\begin{tabular}{lcc}
\hline Unidades fisionômicas & Área (ha) & Percentual de cobertura (\%) \\
\hline Floresta aluvial & 894,5 & 17,9 \\
Floresta submontana & 1714 & 34,3 \\
Capoeira aluvial & 565 & 11,3 \\
Capoeira submontana & 213 & 4,3 \\
Formação pioneira com influência fluvial & 997,5 & 20,0 \\
Campo antrópico & 616 & 12,3 \\
\hline
\end{tabular}


estes autores não permitiu a identificação das áreas remanescentes da cobertura vegetal nesta região.

O estudo mais detalhado, com base no levantamento aerofotogramétrico em escala de 1:20.000, evidenciou a presença de fragmentos de vegetação natural sobre as planícies de inundação e nos morros e morrotes dentro dos limites da Rebio. Com a aplicação do sistema de classificação de vegetação de Veloso \& Goes-Filho (1982), atualizado posteriormente em Veloso et al. (1991), foi possível reconhecer e descrever as características fisionômicas e florísticas destes fragmentos naturais, bem como dos trechos recobertos por vegetação antrópica.

$\mathrm{Na}$ caracterização e mapeamento da cobertura vegetal da Rebio foram identificadas, delimitadas e descritas seis unidades fisionômicas: floresta submontana, floresta aluvial, formação pioneira com influência fluvial, capoeira submontana, capoeira aluvial e campo antrópico (Anexo 1). Os percentuais observados para as diferentes unidades fisionômicas encontram-se apresentados na Tabela 1. Tais percentuais permitem aferir, como cobertura florestal remanescente circunscrita à Rebio, uma área de 2.608,5 hectares, ou seja, $52 \%$ de sua área total. Outra porção muito representativa da área é composta por extensos trechos com cobertura não florestal natural ou resultantes da ação antrópica, expressas por formações pioneiras, capoeiras e campos antrópicos. $\mathrm{Na}$ caracterização florística de cada unidade fisionômica foram indicados os táxons mais representativos ou aqueles que se destacam pelo porte, sempre que possível na categoria de espécies (Tab. 2).

É importante destacar que os percentuais atuais das diferentes fisionomias foram, e ainda continuam sendo, influenciados pelos impactos da construção da Represa de Juturnaiba. As mudanças impactaram, ou até mesmo extinguiram, grandes faixas de florestas aluviais nativas. Alguns trechos foram então inundados, em decorrência do represamento, e, ainda hoje, se mantêm permanentemente alagados. Nestes locais, as árvores mortas, que mantidas ainda eretas e áfilas, sem qualquer presença de vegetação de sub-bosque ao seu redor, podem ser observados como testemunhos das alterações ocorridas. Em vários trechos a jusante da barragem, áreas de florestas e brejos ressequidas sofreram gradativo desaparecimento de sua cobertura original, e vêm ao longo das últimas décadas sendo substituídas por capoeiras e campos antrópicos. Outros trechos com fisionomias campestres são ainda o resultado dos impactos dos freqüentes incêndios - facilitados em grande parte pela natureza do solo turfoso - que interferem periodicamente na paisagem e nos processos naturais de recuperação da área.

\section{Floresta Aluvial}

Unidade fisionômica típica das planícies aluviais sujeitas à influência fluvial, em geral ocupando as áreas de várzeas (Fig. 5) e faixas meândricas do rio São João (Fig. 6). Esta formação abrange uma área de 894,5 hectares, representando 17,9\% da Rebio (Tab. 1).

Os ambientes de floresta aluvial apresentam tipos de solo e condições de inundação bastantes variáveis. Em geral são ambientes muito heterogêneos, formando mosaicos de locais com diferentes níveis de inundação, onde conforme a quantidade e o tempo de permanência da água, a fisionomia pode variar quanto ao porte, ao adensamento dos indivíduos e às espécies características.

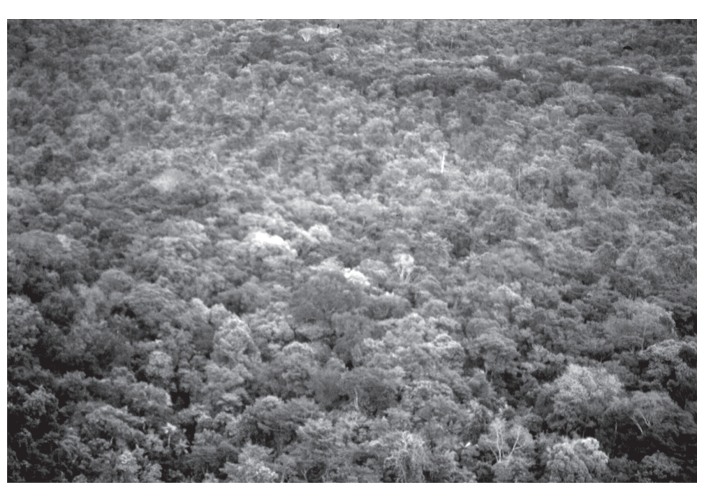

Figura 5 - Floresta aluvial em área de várzea na Reserva Biológica de Poço das Antas, Silva Jardim, Rio de Janeiro. 
Tabela 2 - Lista das espécies mais representativas ou que se destacam na composição florística de cada unidade fisionômica da vegetação da Reserva Biológica de Poço das Antas, Rio de Janeiro. Floresta Aluvial (FA); Floresta Submontana (FS), Capoeira Aluvial (CA), Capoeira Submontana (CS), Formação Pioneira com Influência Fluvial (FP) e Campo Antrópico (CP).

\begin{tabular}{|c|c|c|}
\hline Espécie & Nome vulgar & Unidade fisionômica \\
\hline Acacia lacerans Benth. & Arranha-gato & FS,CS \\
\hline Actinostemon verticillatus (Klotzsch.) Baill. & & FS \\
\hline Aeschynomene sensitiva $\mathrm{Sw}$. & Corticeira & $\mathrm{CA}, \mathrm{FP}, \mathrm{CP}$ \\
\hline Alchornea triplinervia (Spreng.) M. Arg. & Tapiá & FA,FS \\
\hline Anaxagorea dolichocarpa Sprague \& Sandwith & & FS \\
\hline Andira anthelmia (Vell.) Macbr. & Angelim & FA,CA,CP \\
\hline Andropogon bicornis L. & Capim-rabo-de-burro & $\mathrm{CP}$ \\
\hline Annona cacans Warm. & Araticum & FS \\
\hline Apuleia leiocarpa (Vog.) J.F. Macbr. & Garapa & FS \\
\hline Astrocaryum aculeatissimum (Schott) Burret & Irí & FS \\
\hline Attalea humilis Mart. & Pindoba & FS,CS \\
\hline Baccharis dracunculifolia DC. & Alecrim & $\mathrm{CA}, \mathrm{CP}$ \\
\hline Bactris setosa Mart. & Tucum & FA,FP,CA \\
\hline Blechnum serrulatum Rich. & Samambaia & $\mathrm{CA}, \mathrm{CP}$ \\
\hline Cabomba aquatica Aubl. & Cabomba & $\mathrm{FP}$ \\
\hline Calophyllum brasiliense Cambess. & Guanandí & FA \\
\hline Cariniana estrellensis (Raddi) Kuntze & Jequitibá & FS \\
\hline Cariniana legalis (Mart.) Kuntze & Jequitibá-rosa & $\mathrm{FS}$ \\
\hline Casearia sylvestris $\mathrm{Sw}$. & Café-do-mato & FS \\
\hline Cecropia glazioui Snethlage & Embauba & CA,CS,FP,FS \\
\hline Cecropia lyratiloba Miq. & Embauba; embaubinha & $\mathrm{CA}, \mathrm{CP}$ \\
\hline Chondodendron platiphylla (A. St.-Hil.) Miers & Abuta; cipó-bala & FS \\
\hline Cladium jamaicense Crantz & Capim-navalha & $\mathrm{FP}$ \\
\hline Clethra scabra Pers. & Carne-de-vaca & $\mathrm{FS}$ \\
\hline Clidemia biserrata DC. & Pixirica & $\mathrm{CP}$ \\
\hline Costus spiralis (Jacq.) Roscoe & Cana-do-brejo & $\mathrm{CA}$ \\
\hline Cyperus ligularis L. & Tiririca-do-brejo & $\mathrm{FP}$ \\
\hline Dalbergia frutescens (Vell.) Britton & Cipó-de-estribo & $\mathrm{FS}, \mathrm{CS}, \mathrm{CP}$ \\
\hline Diplotropis incexis Rizz. \& Mattos F. & Sucupira & FS \\
\hline Eichhornia crassipes (Mart.) Solms. & Aguapé & $\mathrm{FP}$ \\
\hline Eriotheca pentaphylla (Vell.) A. Robyns & Imbiruçu & FA,FS \\
\hline Euterpe edulis Mart. & Palmito & FS \\
\hline Genipa americana $\mathrm{L}$. & Genipapo & FA \\
\hline Gochnatia polimorpha (Less.) Cabrera & Cambará & CS \\
\hline Guarea guidonia (L.) Sleumer & Carrapeta & FS,CS,CP \\
\hline Guarea macrophylla Vahl & Carrapeta & FS \\
\hline Hedychium coronarium Koern. & Lirio-do-brejo & CA,FP \\
\hline Henriettea saldanhaei Cogn. & Pixiricão & FA,FS \\
\hline Hyparrhenia rufa (Nees) Stapf & Capim-jaraguá & $\mathrm{CP}$ \\
\hline Imperata brasiliensis Trin. & Sapé & $\mathrm{CA}, \mathrm{CS}, \mathrm{CP}$ \\
\hline Inga edulis Mart. & Ingá-cipó & FA,FS \\
\hline
\end{tabular}




\begin{tabular}{|c|c|c|}
\hline Espécie & Nome vulgar & Unidade fisionômica \\
\hline Inga laurina (Sw.) Willd. & Ingá-mirim & FA,CA \\
\hline Inga thibaudiana DC. & Ingá & FA,FS \\
\hline Inga vera Willd. & Ingá-do-brejo & FA \\
\hline Lantana camara $\mathrm{L}$. & Camará & $\mathrm{CP}$ \\
\hline Lonchocarpus cultratus (Vell.) Az.-Tozzi \& H.C. Lima & Embira-de-sapo & $\mathrm{FA}, \mathrm{FS}, \mathrm{CA}, \mathrm{CP}$ \\
\hline Ludwigia quadrangularis (Mich.) H. Hara & Cruz-de-malta & $\mathrm{CA}$ \\
\hline Lygodium volubile $\mathrm{Sw}$. & Abre-caminho & $\mathrm{CP}$ \\
\hline Mabea fistulifera Mart. & Canudeiro & FS \\
\hline Margaritaria nobilis L.f. & Figueirinha & FA \\
\hline Martiodendron mediterraneum (Mart. ex Benth.) Köppen & & FS \\
\hline Melinis minutiflora P. Beauv. & Capim-gordura & $\mathrm{CS}, \mathrm{CP}$ \\
\hline Miconia albicans (Sw.) Triana & Pixirica & $\mathrm{CS}, \mathrm{CP}$ \\
\hline Miconia cinnamomifolia (DC.) Naudin & Jacatirão & FS \\
\hline Miconia staminea (Desr.) DC. & Pixirica & $\mathrm{CP}$ \\
\hline Moldenhawera polysperma (Vell.) Stellfeld & Caingá & FS \\
\hline Monstera adansonii Schott & Imbé & FS \\
\hline Myrcia anceps (Spreng.)O. Berg & Cambuí & FA,FS \\
\hline Nectandra oppositifolia Nees & Canela-louro & CS \\
\hline Nidularium procerum Lindm. & Gravatá & FA \\
\hline Panicum maximum Jacq. & Capim-colonião & CA,CP,FP \\
\hline Pera glabrata (Schott) Baill. & Tabocuva & FA,FS \\
\hline Piptadenia adiantoides (Spreng.) J.F. Macbr. & Arranha-gato & FS \\
\hline Platymenia foliolosa Benth. & Vinhático & FS \\
\hline Platymiscium floribundum Vog. & Sacambu & FA \\
\hline Polygonum acuminatum Kunth. & Erva-de-bicho & $\mathrm{CA}, \mathrm{CP}$ \\
\hline Pourouma guianensis Aubl. & Uvaia & FA,FS \\
\hline Pseudopiptadenia contorta (DC.) G.P. Lewis \& M.P. Lima & Angico & FS \\
\hline Psidium guineense $\mathrm{Sw}$. & Araçá & $\mathrm{CS}, \mathrm{CP}, \mathrm{FS}$ \\
\hline Pteridium aquilinum (L.) Kuhn & Samambaia & CS,CP,FP \\
\hline Rauvolfia grandiflora Mart. ex A.DC. & Pau-leite & $\mathrm{CA}$ \\
\hline Sabicea aspera var. glabrescens (Benth.) Schum. & & $\mathrm{CP}$ \\
\hline Salvinia auriculata Aubl. & Lentilha d'água & FP \\
\hline Schinus terebinthifolius Raddi & Aroeirinha & CA,CP,FS \\
\hline Senefeldera verticillata (Vell.) Croizat & Sucanga & FS \\
\hline Siparuna guianensis Aubl. & Nega-mina & CS \\
\hline Siparuna reginae (Tul.) A. DC. & Nega-mina & FA,FS \\
\hline Sparattosperma leucanthum (Vell.) K. Schum. & Cinco-chagas & $\mathrm{CS}, \mathrm{FS}$ \\
\hline Symphonia globulifera L.f. & Guanandí & FA,CA \\
\hline Tabebuia cassinoides DC. & Ipê-tamanco & FA,CA \\
\hline Tibouchina granulosa (Desv.) Cogn. & Quaresmeira & CS \\
\hline Tovomitopsis paniculata (Spreng.) Planch. \& Triana & Guanadirana & FA,CA,FS \\
\hline Trema micrantha $($ L.) Blume & Crindiuva & CA,CS,FP,FS \\
\hline Typha dominguensis Pers. & Taboa & $\mathrm{FP}$ \\
\hline Vataireopsis araroba (Aguiar) Ducke & Angelim-araroba & FS \\
\hline Xylopia sericea A. St-Hil. & Imbiu-pimenta & FS \\
\hline
\end{tabular}




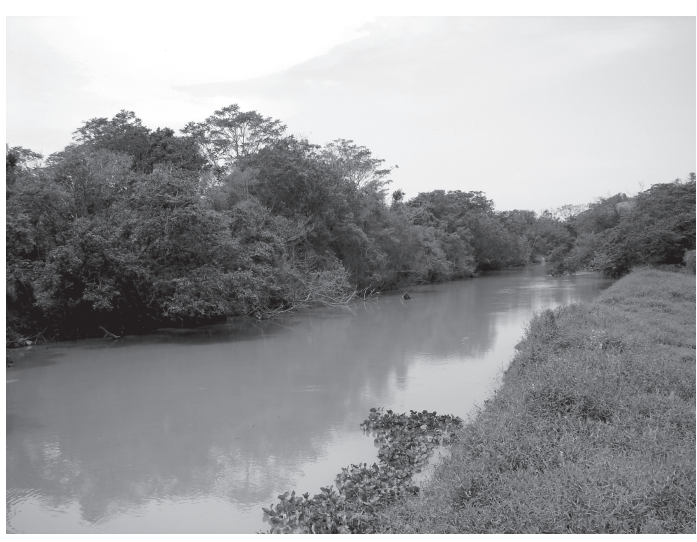

Figura 6 - Floresta aluvial em faixa meandrica do rio São João na Reserva Biológica de Poço das Antas, Silva Jardim, Rio de Janeiro.

Associados a esta fisionomia foram observados Gleissolos, Neossolos Flúvicos, Planossolos e, em menor escala, Organossolos (classes modificadas a partir de Takizawa 1995). Esses quatro tipos de solo são associados a situações na paisagem onde a drenagem ao longo do perfil é imperfeita. $\mathrm{Na}$ maior parte desses solos há um maior acúmulo de matéria orgânica nas camadas superficiais, que se decompõe mais lentamente em condições de hidromorfismo.

É um tipo de vegetação que apresenta fisionomia arbórea dominante, formando um dossel fechado e relativamente uniforme, com raros exemplares emergentes. As árvores do dossel atingem de um modo geral alturas entre 15-18 metros, enquanto as emergentes alcançam nos trechos mais preservados em média 20-27 metros. Nas áreas de várzeas há um predomínio de ipê-tamanco (Tabebuia cassinoides), guanandí (Symphonia globulifera) e guanandirana (Tovomitopsis paniculata), embora outras espécies arbóreas também sejam comuns no dossel. Entre elas destacam-se Alchornea triplinervia, Platymiscium floribundum, Genipa americana, Eriotheca pentaphylla, Myrcia anceps, Calophyllum brasiliense e Pera glabrata. Nas faixas meândricas as espécies arbóreas dominantes são Margaritaria nobilis, Andira anthelmia e várias espécies de Inga (I. edulis, I. laurina, I. thibaudiana e I. vera).
No sub-bosque é freqüente o domínio de indivíduos jovens de ipê-tamanco, guanandí e guanandirana. São ainda comuns nas áreas pouco perturbadas espécies de Myrtaceae Melastomataceae, Palmae, Rubiaceae, Leguminosae, Meliaceae, Moraceae, Euphorbiaceae, entre outras. Arbustos e arvoretas típicas deste estrato ocorrem juntamente com indivíduos jovens de espécies arbóreas do dossel, em processo de recrutamento. No estudo das espécies de Melastomataceae da Rebio (Baumgratz et al. 2006), foi apontado que a família é mais diversificada no sub-bosque, onde está representada por elementos dos gêneros Clidemia, Leandra, Ossaea, Miconia e Tibouchina e pela espécie Henriettea saldanhaei. Este autores destacam ainda que muitas espécies são comuns tanto em morrotes quanto em áreas alagadas.

Em trechos permanentemente inundados ocorrem populações adensadas de tucum (Bactris setosa), enquanto o solo encharcado é coberto por extensas formações de gravatás, sobretudo da espécie Nidularium procerum. Ervas de folhas largas, principalmente espécies de Marantaceae, Heliconiaceae e Costaceae são também muito comuns no estrato herbáceo. A riqueza de epífitas é outra característica notável desta unidade fisionômica, representada principalmente por espécies de Bromeliaceae (Aechmea spp., Bilbergia spp., Vriesea spp. e Tillandsia spp.), Orchidaceae, Araceae (Monstera adansonii) e Cactaceae (Rhipsalis spp.).

No estudo fitossociológico realizado em um trecho de 1 ha desta unidade fisionômica (Guedes-Bruni et al. 2006a) foram amostradas 97 espécies, subordinadas a 31 famílias, cujo índice de diversidade de Shannon $\left(\mathrm{H}^{\prime}\right)$ foi de 3,98 nats/ind, enquanto a eqüabilidade (J) foi de 0,87 . Estes valores de riqueza e diversidade são bastante expressivos, embora mais baixos quando comparados com aqueles observados no estudo realizado em um trecho de floresta submontana da Rebio (GuedesBruni et al. 2006b). 
Em decorrência da construção da Represa de Juturnaíba, a situação atual da floresta aluvial na Rebio reflete as diferentes mudanças ocorridas na altura do lençol freático. Em vários trechos observa-se alterações na composição florística, particularmente no predomínio ou na elevada mortalidade de certas espécies. Como demonstrado por Scarano et al. (1997), essas variações locais na composição e na estrutura deste tipo de floresta podem estar associadas com as diferentes estratégias no estabelecimento das espécies, principalmente em relação a tolerância à duração da inundação.

\section{Floresta Submontana}

Esta unidade fisionômica reveste as áreas elevadas não sujeitas a influência fluvial das encostas dos morros e morrotes mamelonares. Na compartimentação da paisagem da Rebio sobressai uma elevação central formada por uma série de morros e morrotes, cuja altitude varia entre 100 e 200 metros. Morrotes isolados estão distribuídos no entorno dessa elevação, principalmente na porção sudeste onde se expande a planície aluvial. Esta formação abrange uma área de 1714 hectares, representando 34,3\% da Rebio (Tab. 1).

Associados a esta fisionomia foram observados principalmente Argissolos (associação que cobre aproximadamente 30\% da área total da Reserva de Poço das Antas), álicos a moderados, com textura variando de argilosa a muito argilosa. Cambissolo ocorre apenas no Morro da Portuense, o ponto mais alto da Rebio (Takizawa 1995), e há ainda uma associação dessa fisionomia (somente $2 \%$ da área total da Reserva) com gleissolos, na unidade geomorfológica denominada de alvéolo (Takizawa 1995), localizada entre as encostas dos morrotes e as várzeas internas. A ocorrência desses gleissolos explica-se pela drenagem imperfeita da água nesse compartimento, que por sua vez recebe toda argila carreada dos pontos mais altos da paisagem: gleissolos são solos acinzentados pelas condições de hidromorfismo e com alto teor de argila nas camadas superficiais (Embrapa 1999).

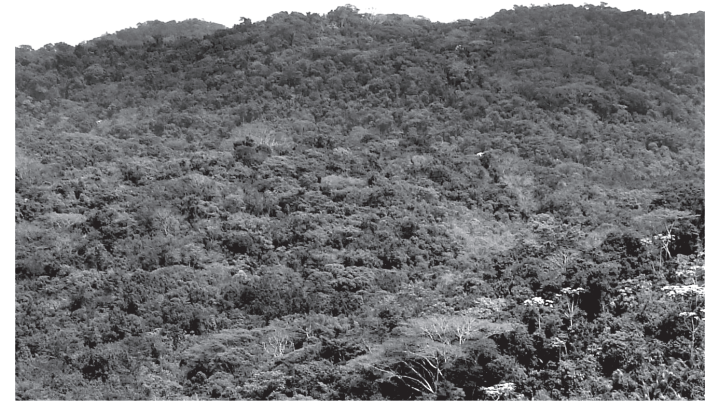

Figura 7 - Floresta submontana bem preservada na Rebio de Poço das Antas, Silva Jardim, Rio de Janeiro.

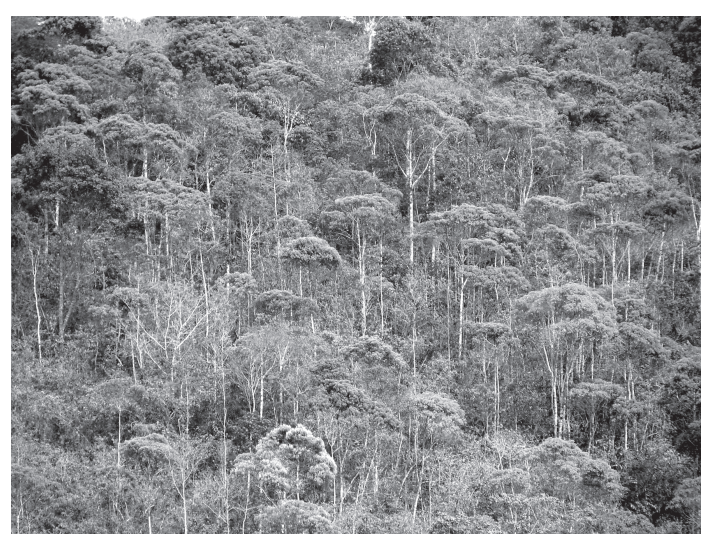

Figura 8 - Floresta submontana degradada na Rebio de Poço das Antas, Silva Jardim, Rio de Janeiro.

Nos locais em bom estado de preservação apresenta fisionomia arbórea dominante, formando um dossel fechado e pouco uniforme e ocorrência de árvores emergentes (Fig. 7). As árvores do dossel atingem alturas entre 17 e 23 metros, enquanto as emergentes alcançam até cerca de 30 metros. Entre as espécies que mais se destacam pelo porte muito elevado estão: jequitibá (Cariniana legalis e Cariniana estrellensis), garápa (Apuleia leiocarpa), figueira (espécies de Ficus), caingá (Moldenhawera polysperma) e vinhático (Platymenia foliolosa). Destacam-se ainda pelo grande número de indivíduos Senefeldera verticillata, Siparuna reginae, Mabea piriri, Casearia sylvestris, Clethra scabra e Pseudopiptadenia contorta. Em alguns trechos, principalmente em grotas úmidas, são ocasionais os adensamentos de 
palmito (Euterpe edulis). Em áreas com histórico de perturbação (Fig. 8), principalmente em florestas secundárias em estados médio a avançado de regeneração, o dossel em geral atinge 10-12 m e, entre as espécies que predominam, sobressaem carrapeta (Guarea macrophylla), jacatirão (Miconia cinnamomifolia), uvaia (Pourouma guianensis) e imbiú-pimenta (Xylopia sericea).

O sub-bosque geralmente é ralo, onde dominam espécies de Myrtaceae, Rubiaceae, Rutaceae, Euphorbiaceae e Melastomataceae, exceto nos locais com histórico de degradação onde aparecem populações adensadas de pindoba (Attalea humilis) e iri (Astrocaryum aculeatissimum). Entre os arbustos e arvoretas mais freqüentes destacam-se as espécies dos gêneros Psychotria, Geonoma, Leandra, Miconia, Actinostemon e Piper. As lianas são abundantes, podendo formar emaranhados nos bordos de mata e clareiras, sendo representadas principalmente por Chondodendron platiphyllum (Menispermaceae) e espécies de Sapindaceae (principalmente de Serjania) e Leguminosae (Acacia lacerans, Piptadenia adiantoides e espécies de Machaerium).

O estrato herbáceo é pouco denso, ocorrendo esparsamente espécies de Marantaceae, Heliconiaceae, Graminea e Cyperaceae, além de Pteridófitas. As epífitas são ocasionais e bem menos representadas nesta unidade vegetacional do que na floresta aluvial.

Guedes-Bruni et al (2006b) em estudo fitossociológico realizado em um trecho de 1 hectare desta unidade fisionômica encontraram 174 espécies, subordinadas a 45 famílias, obtendo valores de 4,549 nats/ind para o índice de diversidade de Shannon $\left(\mathrm{H}^{\prime}\right)$, enquanto a equiabilidade (J) foi de 0,88 . Estes valores são bastante elevados quando comparados com os dados de riqueza e diversidade obtidos no estudo de um trecho de floresta aluvial na Rebio. Segundo os autores estes valores também são muito expressivos quando comparados aos obtidos por estudos em outros trechos de Mata Atlântica (Guedes-Bruni et al 2006a).
A floresta submontana sobre os morrotes de baixa altitude e isolados na extensa planície aluvial mostra um aspecto mais seco, apresentando maior grau de deciduidade no período de junho a agosto. Na composição florística destacam-se as espécies arbóreas Senefeldera verticillata, Actinostemon verticillatus, Anaxagorea dolichocarpa e Annona cacans (Pessoa 2003). Algumas espécies, tais como Martiodendron mediterraneum, Vataireopsis araroba e Diplotropis incexis, até o momento só foram encontradas nestas áreas de morrotes isolados. Estas espécies têm preferência por florestas estacionais (Lima 2000), mostrando que futuros estudos poderão indicar diferenças na composição florística de florestas sobre morrotes isolados.

Embora algumas espécies tenham sido encontradas apenas em florestas de morros mais baixos e isolados, variações na composição florística e na estrutura no gradiente altitudinal da Rebio não são expressivas. Estudos realizados em toposequência na região da Bacia do Rio São João (Borém \& Ramos 2001; Borém \& Oliveira-Filho 2002), mostraram pouca diferenciação ao longo da toposequência e confirmam essa observação.

Em decorrência da forte ação antrópica em passado recente, os ambientes com esta fisionomia mostram-se atualmente como um mosaico de áreas em diversos estádios sucessionais. As áreas mais preservadas estão em geral localizadas nas encostas de alguns morros e morrotes com maior dificuldade de acesso. Porém, devido ao histórico de exploração de madeira da área, particularmente a extração de lenha e carvão (IBDF/FBCN 1981), é provável que mesmo estes trechos em melhor estado de preservação tenham sofrido perturbações antrópicas.

Neves (1999) analisou dois trechos de diferentes idades (20 e 40 anos) em floresta submontana da Rebio. Apesar das diferenças na composição e estrutura da comunidade arbóreo-arbustiva, foi evidenciada a alta 
capacidade de regeneração nas duas áreas. A autora sugeriu ainda que trechos de florestas secundárias precisam no mínimo 40 anos para obter as características florísticas mais próximas de florestas preservadas. Considerando estes resultados, embora reconhecendo que as áreas nos limites da Rebio ainda sofram impactos antrópicos, pode-se admitir que boa parte das florestas secundárias sobre morros e morrotes estão avançando no processo de sucessão natural. É provável que para isto estejam contribuindo os fragmentos florestais em bom estado de preservação.

\section{Capoeira Aluvial}

Unidade fisionômica resultante de processos naturais de sucessão, após a supressão total ou parcial, por ações antrópicas, da cobertura arbórea em áreas de floresta aluvial, podendo ocorrer árvores remanescentes da vegetação primária. A fisionomia varia conforme o estádio sucessional, sendo ainda fortemente influenciada pela intensidade nas mudanças ocorridas nas condições locais, principalmente pelas alterações no regime hídrico.

Aos ambientes de capoeira aluvial, de modo semelhante à floresta aluvial, estão associados os Gleissolos, Planossolos, Neossolos Flúvicos e Organossolos (Takizawa 1995). Portanto, as diferenças florísticas e estruturais dessa fisionomia com a floresta aluvial resultam de ações antrópicas pretéritas e, de modo geral, não devem ser associadas aos tipos de solos. Esta formação abrange uma área de $565 \mathrm{ha}$, representando 11,3\% da Rebio (Tab. 1).

Os elementos arbóreos variam entre 3 e 5 metros de altura, observando-se variados padrões fisionômicos de acordo com as espécies dominantes (Figs. 9 e 10). Adensamentos de indivíduos jovens de ipêtamanco (Tabebuia cassinoides), ou guanandí (Symphonia globulifera), ou tucum (Bactris setosa), ou embaubinha (Cecropia lyratiloba) são os padrões mais

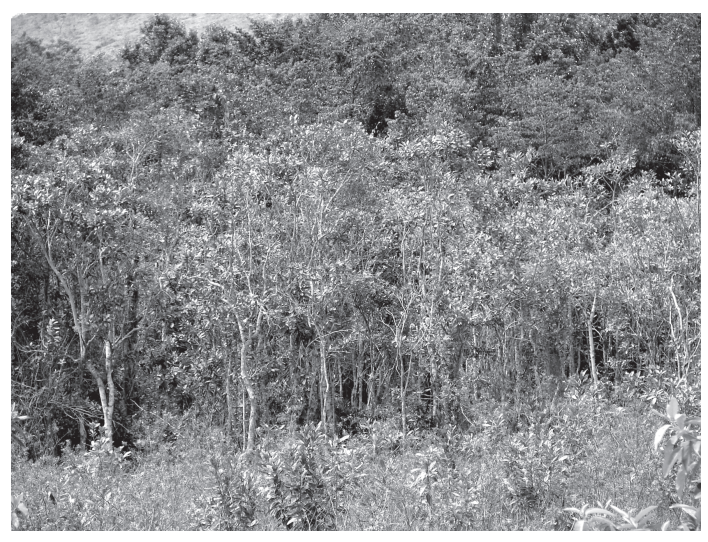

Figura 9 - Capoeira aluvial com adensamento de ipêtamanco (Tabebuia cassinoides) na Rebio de Poço das Antas, Silva Jardim, Rio de Janeiro.

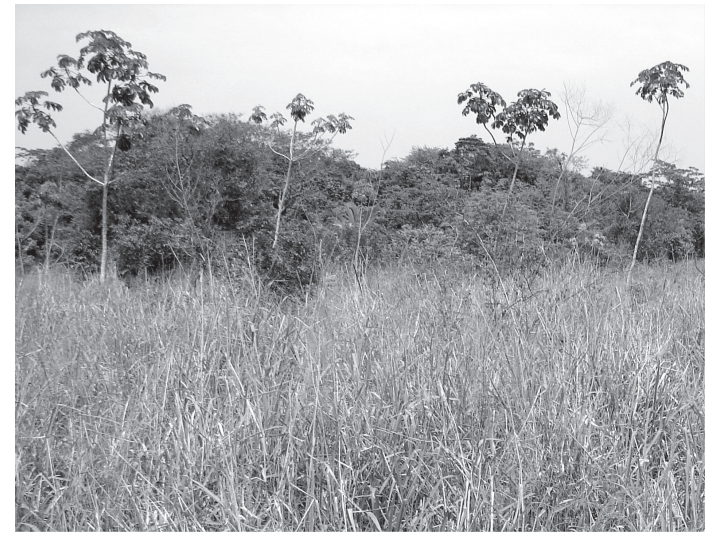

Figura 10 - Capoeira aluvial com embaubinha (Cecropia lyratiloba) na Rebio de Poço das Antas, Silva Jardim, Rio de Janeiro.

comuns. Além dessas espécies arbóreas, com certa freqüência são observados exemplares de Inga laurina, Andira anthelmia e Rauvolfia grandiflora. Em planícies aluviais com grande extensão de áreas degradadas, que foram submetidas a drásticas mudanças no regime hídrico, estes adensamentos homogêneos de espécies acima citadas distribuem-se em mosaicos. Nos locais mais impactados podem ser percebidas manchas diferenciadas, onde predominam Schinus terebinthifolius, Trema micrantha e Cecropia glazioui.

Entre as plantas arbustivas mais comuns destacam-se espécies de Rubiaceae (Psychotria spp.), Melastomataceae (Leandra spp., Clidemia biserrata, Miconia 
spp. e Tibouchina spp.), Piperaceae (Piper spp.), Compositae (Baccharis dracunculifolia) e Leguminosae (Aeschynomene sensitiva). $\mathrm{O}$ estrato herbáceo em geral é dominado por espécies ruderais, entre as quais predominam Polygonum acuminatum, Blechnum serrulatum, Imperata brasiliensis e Panicum maximum. Em locais geralmente sujeitos a inundação permanente observa-se a ocorrência de Hedychium coronarium, Costus spiralis e Ludwigia quadrangularis.

As condições de inundação, como já referido para floresta aluvial, estão entre os principais fatores limitantes ao estabelecimento das espécies nesta unidade fisionômica. É interessante ressaltar que algumas espécies utilizam a reprodução vegetativa para recolonizar trechos degradados sujeitos a inundação. Esta estratégia foi observada por Scarano et al. (1997) em Tabebuia cassinoides e Tovomitopsis paniculata.

\section{Capoeira Submontana}

Unidade fisionômica resultante de processos naturais de sucessão, após a supressão total ou parcial, por ações antrópicas, da cobertura arbórea em áreas de floresta submontana, podendo ocorrer árvores remanes-centes da vegetação primária. Apresenta grande variação fisionômica, que é influenciada principalmente pelo estado sucessional e pela forma de vida das espécies dominantes. Associados a esta fisionomia foram observados principalmente Argissolos, álicos a moderados, com textura variando de argilosa a muito argilosa (Takizawa 1995). É importante ressaltar que, no caso de áreas que sofreram impactos antrópicos, como as capoeiras submontanas, $\mathrm{o}$ alto teor de alumínio pode prejudicar o processo de regeneração, interferindo no processo de decomposição da matéria orgânica do solo e dificultando o estabelecimento de um número maior de espécies arbóreas. Esta formação abrange uma área de 213 ha, representando 4,3\% da Rebio (Tab. 1).
Os elementos arbóreos variam entre 3 e 7 metros de altura, observando-se variados padrões fisionômicos de acordo com as espécies dominantes. Adensamentos das espécies pixirica (Miconia albicans) e pindoba (Attalea humilis) são os padrões mais comuns em trechos degradados em encostas de morros e morrotes.

Locais com histórico de pertubação mais recente em geral são ocupados por fisionomia arbustiva monodominante de pixirica (Miconia albicans) (Fig. 11). Ainda não se tem conhecimento se a alta incidência dessa espécie pode estar associada a um fator alelopático que dificulta o estabelecimento de outras espécies. Entre as espécies que ocorrem ocasionalmente nesta formação foram observadas Psidium guineense, Clidemia biserrata e Baccharis dracunculifolia. Raros exemplares de cambará (Gochnatia polimorpha) foram observados nos bordos de capoeiras com adensamento de pixirica, porém não existem estudos sobre o processo sucessional.

Áreas com adensamento de cambará (Gochnatia polimorpha) apresentam fisionomias que variam desde arbustiva até arbórea (Fig. 12). Em geral ocorrem formações monodominantes, porém em muitos trechos são observados exemplares arbustivos ou arborescentes dispersos associados com capim gordura (Melinis minutiflora). Esta situação parece ser a fase inicial do processo sucessional destas capoeiras. Neves (1999) mencionou que esta espécie é muito eficiente na colonização de ambientes alterados, viabilizando o estabelecimento de outras espécies. Em fases sucessionais mais avançadas, outras espécies, tais como Nectandra oppositifolia, Tibouchina granulosa, Sparattosperma leucanthum e Siparuna guianensis, são tão comuns quanto o cambará.

A presença de capoeiras com adensamento de pindoba (Attalea humilis) geralmente é observada em áreas abertas no topo de elevações, em geral próximo a bordos 
de fragmentos florestais. Esta ocorrência possivelmente é influenciada pela alta incidência de incêndios que proporcionam as condições ideais para o desenvolvimento desta espécie, ou seja, ambientes abertos com abundância de luz. Na Rebio a palmeira Attalea humilis pode ser encontrada tanto em ambiente de clareira de floresta como em locais perturbados (Souza \& Martins 2004). Esta também é a preferência da embaúba (Cecropia glazioui), outra espécie muito comum nas capoeiras submontanas da Rebio.

\section{Formação pioneira com influência fluvial}

Vegetação herbácea ou arbustiva de planícies fluviais e depressões aluviais como pântanos e lagoas, sujeitas a inundações periódicas e/ou permanentes. Esta formação abrange uma área de 997,5 ha, representando 20,0\% da Rebio (Tab. 1).

Associados a esta fisionomia foram observados principalmente Organossolos e Gleissolos, que ocorrem em áreas alagadiças em várzeas extensas e ao longo de córregos e dos rios São João e Aldeia (Takizawa 1995). Ambos os solos dificultam a colonização por um número maior de espécies lenhosas, seja pela acidez acentuada do solo (Takizawa 1995), seja pela condição de alagamento mais duradouro. Os baixos valores de $\mathrm{pH}$ dos Organossolos da Rebio têm origem tiomórfica, devido à drenagem artificial em muitos trechos da região.

É um complexo vegetacional com grande variação na fisionomia conforme a altura da lâmina da água e tempo de permanência desta. As comunidades de plantas aquáticas natantes ou submersas são constituídas principalmente por aguapé (Eichhornia crassipes), cabomba (Cabomba aquatica) e lentilha-d'água (Salvinia auriculata). Estas plantas ocorrem nas várzeas permanentemente alagadas e em alguns trechos, em geral meandros muito pronunciados, do rio São João (Fig. 13). Algumas áreas alagadas, em geral no entorno da barragem, foram invadidas por gramíneas aquáticas, principalmente algumas espécies do gênero Brachiaria.

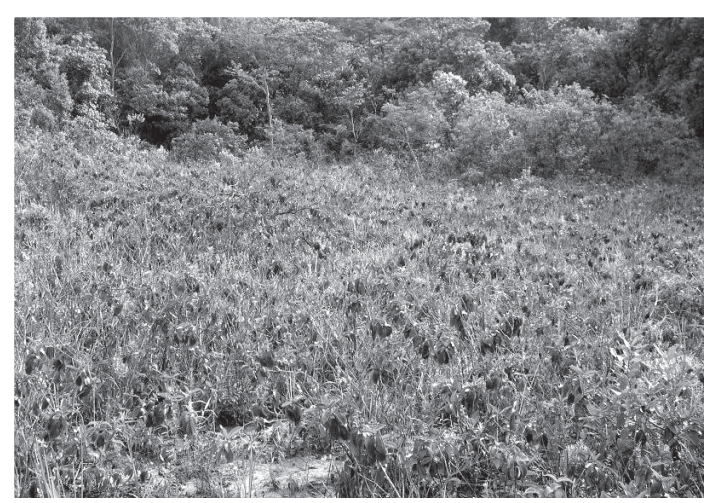

Figura 11 - Capoeira submontana com adensamento de pixirica (Miconia albicans) na Rebio de Poço das Antas, Silva Jardim, Rio de Janeiro.

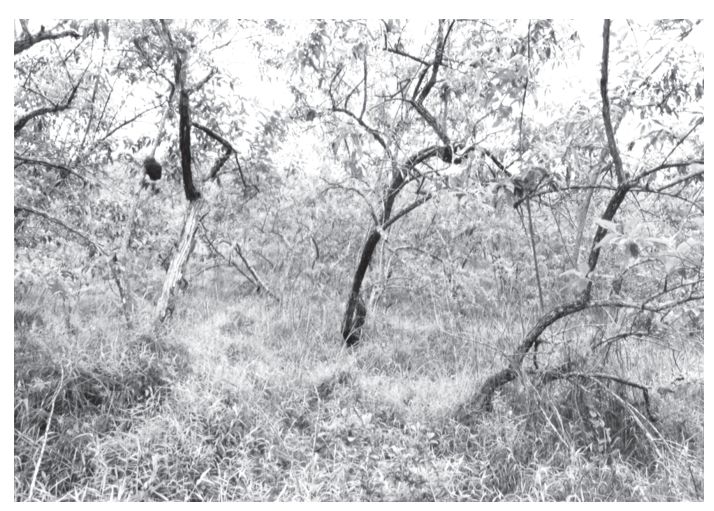

Figura 12- Capoeira submontana com adensamento de cambará (Gochnatia polimorpha) na Rebio de Poço das Antas, Silva Jardim, Rio de Janeiro.

Em comunidades de plantas aquáticas graminóides, geralmente fixadas no substrato, predominam a tabôa (Typha dominguensis) e várias espécies de Cyperaceae, entre as quais predominam Cladium jamaicense e Cyperus ligularis (Fig. 14). Associadas a este complexo de vegetação de áreas alagadiças, ocorrem trechos de turfeiras formadas principalmente por Sphagnum sp. Comunidades de plantas arbustivas lenhosas ocorrem, geralmente, na periferia de locais inundados, onde domina o tucum (Bactris setosa).

Na região sudeste da Rebio, abaixo da Represa de Juturnaíba, encontra-se uma grande planície de inundação, onde este tipo de formação apresenta sua maior extensão, circundando pequenos morrotes e alguns trechos de capoeiras aluviais. Alguns trechos 


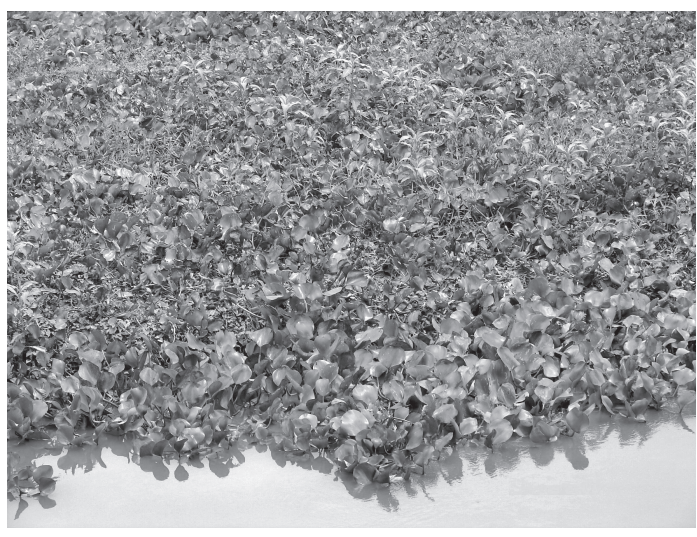

Figura 13 - Formação pioneira com influência fluvial com plantas aquáticas natantes na Rebio de Poço das Antas, Silva Jardim, Rio de Janeiro.

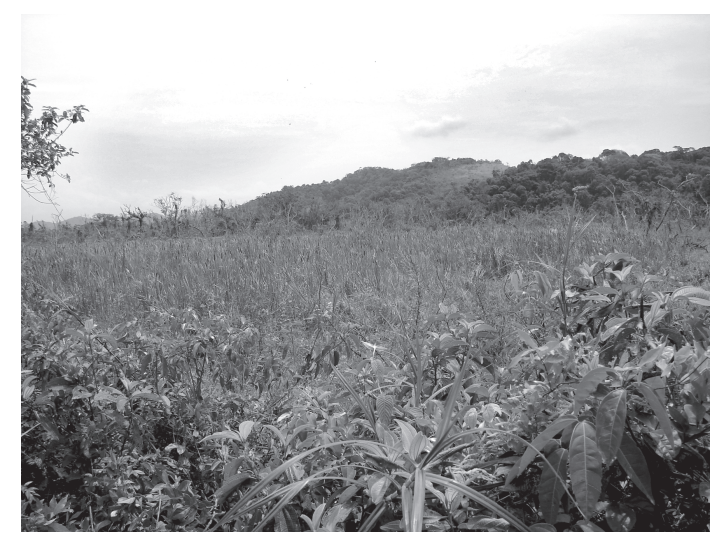

Figura 14 - Formação pioneira com influência fluvial com plantas aquáticas graminoides na Rebio de Poço das Antas, Silva Jardim, Rio de Janeiro.

desta região foram alterados por impactos antrópicos, particularmente onde dominam várias espécies de gramíneas, principalmente Panicum maximum e Imperata brasiliensis, bem como densos agrupamentos da samambaia Pteridium aquilinum. As espécies arbóreas Cecropia glazioui e Trema micrantha podem ocorrer dispersas ou formando pequenos aglomerados, normalmente caracterizados unicamente pela presença de apenas uma destas ou de ambas as espécies (Silva-Matos et al. no prelo).

Em geral distribuída nas áreas limítrofes da Rebio, esta fisionomia encontra-se bastante sujeita a incêndios, particularmente nos períodos mais secos, e sua cobertura vegetal fortemente influenciada por sua ação. SilvaMatos et al. (no prelo) apontam a fragilidade dos elementos arbóreos deste ambiente. Embora apresentando diferentes estratégias em resposta à ação do fogo, seja através da emissão de grande quantidade de plântulas (Trema micrantha) ou da emissão de rebrotos (Cecropia glazioui), ambas se mostram incapazes de competir com a rápida e eficiente regeneração das gramíneas e samambaias. Vale ressaltar a baixa resistência de $T$. micrantha a condições extremas de alagamento que, via de regra, ocasionam a morte dos indivíduos.

\section{Campo antrópico}

Unidade fisionômica resultante da ação antrópica, prioritariamente, pelo uso da terra para atividades agropecuárias, abrangendo grandes extensões de solos empobrecidos, ao mesmo tempo que bastante vulneráveis à ação do fogo (Figs. 15 e 16). Estes ambientes campestres estão associados majoritariamente com Argissolos, nas áreas de morrote, e com associações entre Neossolos Flúvicos, Planossolos e Gleissolos (Takizawa 1995), nas unidades geomorfológicas de deposição aluvional, como as várzeas. Esta formação abrange uma área de 616 hectares, representando 12,3\% da Rebio (Tab. 1).

Nestas áreas predominam, principalmente, plantas invasoras como sapé (Imperata brasiliensis), capim-gordura (Melinis minutiflora), capim-colonião (Panicum maximum) e samambaia (Pteridium aquilinum). Algumas espécies arbustivas, mais tolerantes à luz e à seca, ocorrem consorciadas às gramíneas: alecrim (Baccharis spp), araçá (Psidium guineense), pixirica (Miconia albicans e Clidemia biserrata), camará (Lantana camara), embaúba (Cecropia lyratiloba) e aroeirinha (Schinus terebinthifolius).

Vieira \& Pessoa (2001) estudando esta fisionomia em área de várzea, apontam a distribuição espacial de algumas espécies sobre forte influência das condições edáficas. A espécie Hedychium coronarium, por exemplo, 
forma agrupamentos densos onde o solo apresenta maiores teores de umidade podendo permanecer, muitas vezes, alagado em determinados períodos do ano. Andropogon bicornis, Imperata brasiliensis, Hyparrhenia rufa e Panicum maximum predominam em áreas mais secas enquanto outras espécies, a exemplo de Polygonum acuminatum e Aeschynomene sensitiva, são típicas de áreas mais úmidas, porém não encharcadas. As autoras destacam também, o predomínio de espécies de gramíneas, Imperata brasiliensis, Hyparrhenia rufa, Panicum maximum e de ervas perenes, a exemplo de Sabicea aspera var. glabrescente, Clidemia biserrata e Scleria sp. e de algumas samambaias como Lygodium volubile e Blechnum serrulatum. Estes grupos (gramíneas, ervas perenes e samambaias) apresentam características que atuam fortemente no processo sucessional da comunidade, e

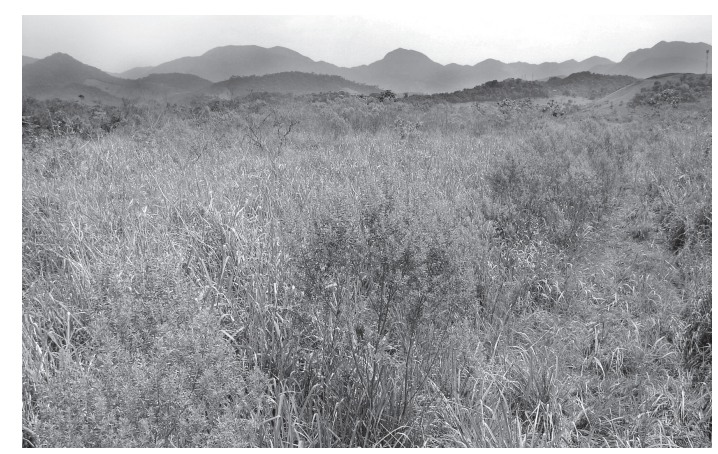

Figura 15 - Campo antrópico com domínio de sapé (Imperata brasiliensis), capim-colonião (Panicum maximum) e alecrim (Bacharis dracunculifolia) na Rebio de Poço das Antas, Silva Jardim, Rio de Janeiro.

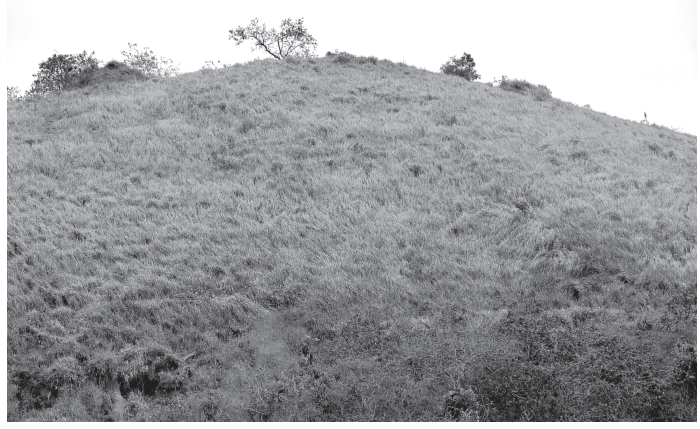

Figura 16 - Campo antrópico com domínio de capimgordura (Melinis minutiflora) na Rebio de Poço das Antas, Silva Jardim, Rio de Janeiro. representam obstáculos à ocorrência de mudanças que propiciem a formação de uma cobertura florestada na paisagem.

Um outro aspecto observado por Vieira \& Pessoa (2001) refere-se à estratégia de restauração da cobertura vegetal destes ambientes. Indivíduos lenhosos uma vez conseguindo ultrapassar a camada de gramíneas, e se estabelecendo no terreno, como exemplares de Miconia staminea, Andira anthelmia, Dalbergia frutescens, Lonchocarpus cultratus e Guarea guidonia acabam por constituírem, pequenos aglomerados de uma ou mais espécies dando início a formação de moitas. Estas, à medida em que ocorre seu crescimento em tamanho, acabam por favorecer o estabelecimento destas e de outras espécies arbustivas e arbóreas.

\section{Conclusões}

O mapeamento da vegetação da Rebio, realizado por meio de fotointerpretação e usando fotografias aéreas na escala 1:20.000, mostrou-se muito eficiente para uma análise detalhada das diferentes fito-fisionomias. Foram delimitados, respectivamente, 2.608 hectares de áreas com florestas em variados estádios sucessionais, 997,5 hectares de formação pioneira com influência fluvial e 1.232 hectares com cobertura não florestal resultantes da ação antrópica, expressas por capoeiras e campos antrópicos. Este resultado é uma primeira aproximação da situação atual da vegetação desta unidade de conservação, que poderá ser utilizado como marco para futuras avaliações e monitoramento.

A despeito do histórico de uso e dos impactos ocorridos em anos recentes, particularmente a alta freqüência de incêndios, ainda é significativo o montante de $52 \%$ de cobertura florestal remanescente. $\mathrm{O}$ que por um lado torna relevante este percentual, por outro ressalta a fragilidade em que os mesmos se encontram, face a presença de áreas antropizadas no entorno 
desta unidade de conservação. Os resultados do mapeamento, em especial a delimitação das áreas com vegetação natural, subsidiam a execução de ações emergenciais que minimizem situações de risco.

O reconhecimento das áreas em melhor estado de preservação se constituirá em ferramenta fundamental para os projetos de pesquisa em realização, ou a serem implementados. Por outro lado, a delimitação das áreas degradadas será de grande utilidade para dimensionar o esforço necessário em estratégias de recuperação dessas áreas. Considerando ainda que a Rebio possui um representativo remanescente de formações florestais da Bacia do Rio São João, revela-se o alto potencial da área para o estabelecimento de matrizes arbóreas para acompanhamento fenológico, coleta de sementes e produção de mudas de espécies nativas.

Por último destaca-se a necessidade de continuidade de monitoramento da cobertura vegetal, fazendo os ajustes necessários e adequando os resultados para o uso de técnicas de sensoriamento remoto. Isto permitirá o acompanhamento de mudanças com metodologia de maior precisão e ampliará a capacidade de previsibilidade de futuros cenários no processo de regeneração das áreas degradas da Rebio.

\section{Agradecimentos}

Ao Jardim Botânico do Rio de Janeiro pelo apoio ao Programa Mata Atlântica; a The John D. and Catherine T. MacArthur Foundation e à Petrobras, cuja alocação de recursos financeiros de longo prazo propiciam a execução dos objetivos do Programa Mata Atlântica do JBRJ; aos colegas do Programa Mata Atlântica que, valendo-se de um objetivo comum, através de suas diferentes linhas de pesquisas, auxiliaram no processo de obtenção de dados no campo e interpretação de alguns resultados obtidos; aos especialistas que revisaram as identificações do material botânico procedente dos vários projetos desenvolvidos na Rebio; à Dorothy S. D.
Araújo pela revisão do abstract; aos funcionários do IBAMA, em especial a Dionisio M. Pessamiglio, Whitson José da Costa Jr. e Rafael Puglia Neto pelo apoio às atividades de campo e disponibilização de vários documentos sobre a Rebio.

\section{REFERÊNCIAS BIBLIOGRÁFICAS}

Baumgratz, J. F. A.; Souza, M. L. R.; Carraça, D. C. \& Abbas, B. A. 2006. Melastomataceae na Reserva Biológica de Poço das Antas: aspectos florísticos e taxonômicos. Rodriguésia 57(3): 591-646.

Bernardes, L. N. C. 1952. Tipos de clima do estado do Rio de Janeiro. Revista Brasileira de Geografia 14(1): 57-80.

Borém, R. A. T. \& Ramos, D. P. 2001. Estrutura fitossociológica da comunidade arbórea de uma topossequiência alterada de uma área de floresta atlântica, no município de Silva Jardim-RJ. Revista Árvore 25(1): 131-140.

\& Oliveira-Filho, A. T. 2002. Fitossociologia do estrato arbóreo em uma toposseqüência alterada de mata atlântica, no município de Silva Jardim-RJ, Brasil. Revista Árvore 26(6): 727-742.

Carauta, J. P. P.; Vianna, M. C.; Araújo, D. S. D. \& Oliveira, R. F. 1978. A vegetação de "Poço das Antas". Bradea 2(46): 299305.

Cardoso-Leite, E.; Pagani, M. I.; Monteiro, R. \& Hamburger, D .S. 2005. Ecologia da paisagem: mapeamento da vegetação da Reserva Biológica da Serra do Japi, Jundiaí, SP, Brasil. Acta Botanica Brasilica 19(2): 233-243.

Cunha, S. B. 1995. Impactos das obras de engenharia sobre o ambiente biofísico da Bacia do rio São João (Rio de Janeiro Brasil). Instituto de Geociências UFRJ, Rio de Janeiro, 380p.

EMBRAPA. 1999. Sistema brasileiro de classificação de solos. Embrapa Produção de Informação, Brasília; Embrapa Solos, Rio de Janeiro. 412p. 
Guedes-Bruni, R. R. 1998. Composição, estrutura e similaridade florística de dossel em seis unidades de Mata Atlântica no Rio de Janeiro. Tese de Doutorado. Universidade de São Paulo, São Paulo, 203p.

Guedes-Bruni, R. R.; Silva Neto, S. J.; Morim, M.P. \& Mantovani, W. 2006a. Composição florística e estrutura de trecho de Floresta Atlântica sobre planície aluvial na Reserva Biológica de Poço das Antas, Silva Jardim, RJ. Rodriguesia 57(3): 413-428.

2006b. Composição florística e estrutura de trecho de Floresta Atlântica sobre morrote mamelonar na Reserva Biológica de Poço das Antas, Silva Jardim, RJ. Rodriguesia 57(3): 429-442.

IBDF/FBCN. 1981. Plano de Manejo da Reserva Biológica de Poço das Antas. Brasília. Instituto Brasileiro de Desenvolvimento Florestal/Fundação Brasileira para a Conservação da Natureza. 95 p.

IBGE. 1992. Mapa de vegetação do Brasil. Rio de Janeiro.

Lamego, A. R. 1946. O homem e a restinga. Rio de Janeiro. IBGE/CNG, 227p.

Lima, H. C. 2000. Leguminosas arbóreas da Mata Atlântica. Uma análise da riqueza, padrões de distribuição geográfica e similaridades florísticas em remanescentes florestais do estado do Rio de Janeiro. Tese de Doutorado. Universidade Federal do Rio de Janeiro, Rio de Janeiro, 151p.

Luccock, J. 1951. Notas sobre o Rio de Janeiro e partes meridionais do Brasil (1808 a 1818). Rio de Janeiro. Biblioteca Histórica Brasileira, 435p.

Matovani, W. 1987. Análise florística e fitossociológica do estrato herbáceosubarbustivo do cerrado na Reserva Biológica de Mogi-Guaçu e em Itirapina, SP. Tese de Doutorado. Universidade Estadual de Campinas, Campinas, 203p.

Neves, G. M. S. 1999. Florística e estrutura da comunidade arbustivo-arbórea em dois remanescentes de Floresta Atlântica secundária - Reserva Biológica de Poço das Antas, Silva Jardim, RJ. Dissertação de Mestrado. Universidade Federal do Rio de Janeiro, Museu Nacional, Rio de Janeiro, 115p.

Noffs, M. S. \& Baptista-Noffs, L. J. 1982. Mapa da vegetação do Parque Estadual da Ilha do Cardoso - as principais formações. Revista do Instituto Florestal 16A(1): 613-619.

Oliveira , M. L. A. A. \& Porto, M .L. 1999. Ecologia da paisagem do Parque Estadual do Delta do Jacuí, Rio Gande do Sul, Brasil: mapa da cobertura do solo e vegetação, a partir de imagem do LANDSAT TM5. Iheringia, Série Botânica 53: 89-144.

Pessoa, S. V. A. 2003. Aspectos da fragmentação em remanescentes florestais da planície costeira do estado do Rio de Janeiro. Dissertação de Mestrado. Universidade Federal Rural do Rio de Janeiro, Seropédica. 111 p.

Primo, P. B. S. \& Völcker, C. M. 2003. Bacias Hidrográficas dos rios São João e das Ostras: águas, terras e conservação ambiental. Rio de Janeiro. Consórcio Intermunicipal para Gestão das Bacias Hidrográficas da região dos Lagos, Rio São João e Zona Costeira CILSJ, 170p.

Scarano, F. R.; Ribeiro, K. T.; Moraes, L. F. D. \& Lima, H. C. 1997. Plant establishment on flooded and unflooded patches of a freshwater swamp forest in southeastern Brazil. Journal of Tropical Ecology 14: 793-803.

Silva-Matos, D. M.; Fonseca, G. D. F. M. \& Silva-Lima, L. (no prelo). Differences on post-fire regeneration of the pioneers Cecropia glazioui and Trema micrantha in a lowland Brazilian Atlantic Forest. Revista de Biologia Tropical.

Souza, A. F. \& Martins, F. R. 2004. Spatial distribution of an undergrowth palm in fragments of the Brazilian Atlantic Forest. Plant Ecology 164: 141-155. 
Takizawa, F. H. 1995. Levantamento pedológico e zoneamento ambiental da Reserva Biológica de Poço das Antas. Monografia de Graduação. Escola Superior de Agricultura Luis de Queiroz/ USP, Piracicaba, 56p.

Ururahy, J. C. C.; Collares, J. E. R.; Santos, M. M. \& Barreto, R. A. A. 1983. Vegetação. In: RADAMBRASIL. Folhas SF. 23/24 Rio de Janeiro/Vitória, Levantamento de Recursos Naturais 32: 553-623.

Veloso,H.P. \& Góes-Filho, L. 1982. Fitogeografia Brasileira. Classificação fisionômico- ecológica da vegetação neotropical. Boletim Técnico Projeto RADAMBRASIL, Série Vegetação 1: 1-79.

Veloso, H. P. ; Rangel-Filho, A. L. R. \& Lima, J. C. A. 1991. Classificação da vegetação brasileira adaptada a um sistema universal. Rio de Janeiro. IBGE, 123 p.

Vieira, C. M. \& Pessoa, S. V.A. 2001. Estrutura e composição florística do estrato herbáceo-subarbustivo de um pasto abandonado na Reserva Biológica de Poço das Antas, município de Silva Jardim, RJ. Rodriguésia 52(80): 17-29. 
Anexo 1 - Mapa da Vegetação da Reserva Biológica de Poço das Antas, Silva Jardim, Rio de Janeiro

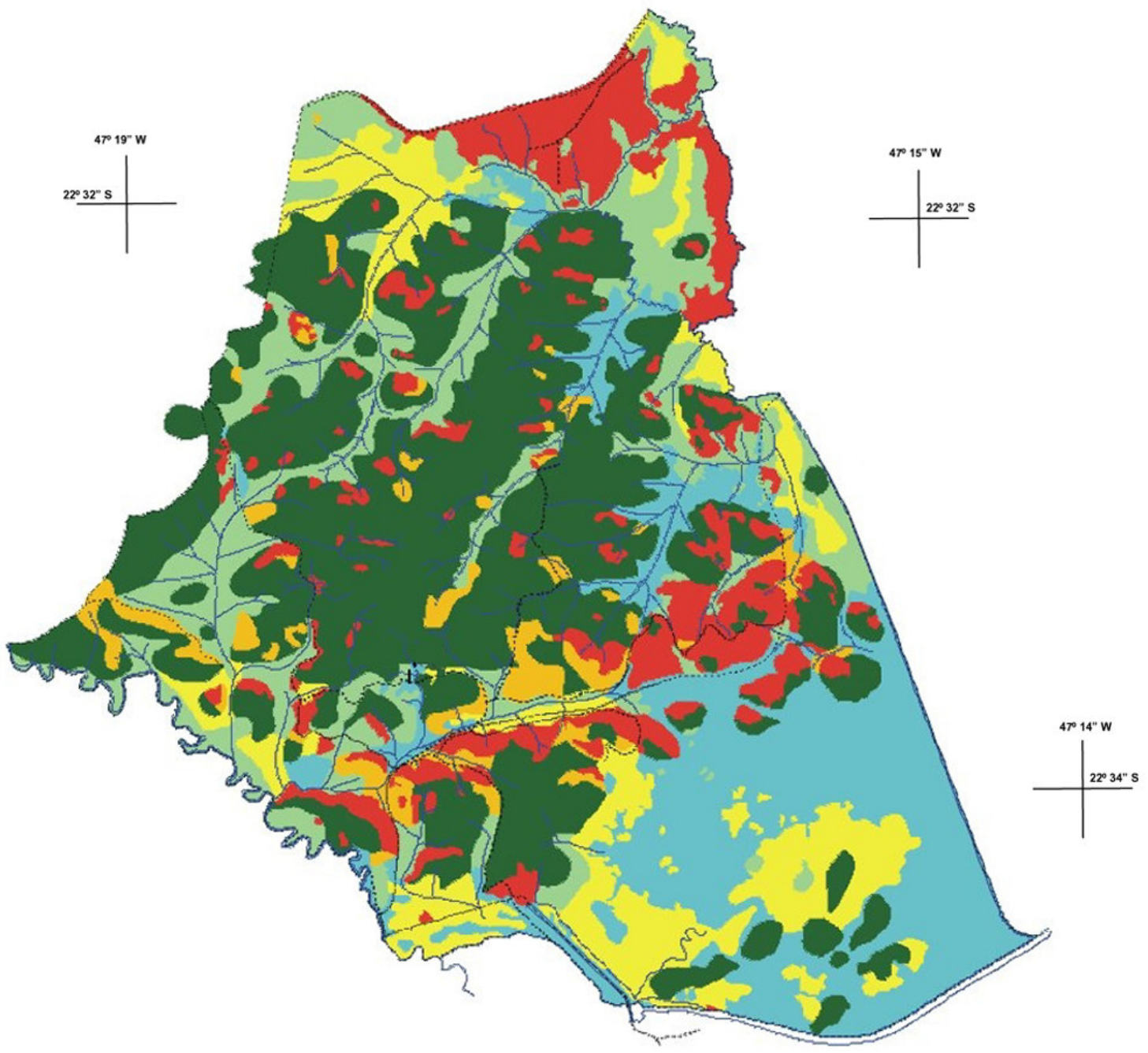

UNIDADES FISIONÔMICAS

$\begin{aligned} & \text { FLORESTA SUBMONTANA } \\ & \text { FLORESTAALUVIAL } \\ & \text { FORMAÇÃO PIONEIRA COM INFLUÊNCIA FLUVIAL } \\ & \text { CAPOEIRA SUBMONTANA } \\ & \text { CAPOEIRA ALUVIAL } \\ & \text { CAMPO ANTRÓPICO } \\ & \because \text { Estradas } \\ & \triangle \text { Hidrografia }\end{aligned}$

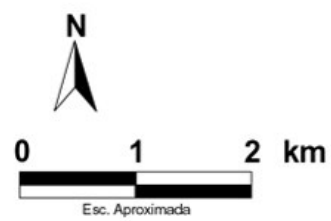

